\title{
Professional accountability for diabetes care in Taiwan
}

\author{
Fen-Yu Tseng ${ }^{\mathrm{a}, \mathrm{b}}$, Mei-Shu Lai ${ }^{\mathrm{b}, *}, \mathrm{Ci}^{-}$Yong Syu ${ }^{\mathrm{b}}$, Cheng-Ching Lin ${ }^{\mathrm{c}}$ \\ ${ }^{a}$ Department of Internal Medicine, National Taiwan University Hospital and National Taiwan University College of Medicine, No. 7 , \\ Chung-Shan South Road, 100 Taipei, Taiwan \\ ${ }^{\mathrm{b}}$ Institute of Preventive Medicine, College of Public Health, National Taiwan University, Taipei, Taiwan \\ ${ }^{\mathrm{c}}$ Department of Family Medicine, Taipei Medical University Municipal Wan-Fang Hospital, Taiwan
}

Received 14 January 2005; received in revised form 22 April 2005; accepted 20 June 2005

Available online 8 August 2005

\begin{abstract}
This study examined the performance of diabetes care measures in Taiwan and evaluated the influencing factors for professional accountability. We analyzed the year 2001 claims data from National Health Insurance (NHI) program in Taipei Branch. Professional accountability for diabetes care was measured by the adherence for laboratory monitor, either from patientor hospital-viewpoint. Identifying the major care unit for each patient, a multiple logistic regression model was used to further assess the mixed effects of patient and hospital characteristics. The percentage of patients ever received measures in the year for plasma glucose, $\mathrm{A}_{1 \mathrm{C}}$, urinalysis, renal function test, lipid profile, liver function test, and eye ground was 76.3, 42.7, 40.2, 59.7, 59.2, 53.2, and $16.8 \%$ respectively. About $19.2 \%$ patients never received any one of the measures. Patients with hypoglycemic, anti-hypertensive or anti-hyperlipidemic agents, hospitalization, emergency service visit and frequent visits were more likely to receive exams. Hospitals with different levels, ownerships, locales or qualifications as diabetes care institutions presented different accountability for diabetes care measures. After regression, counts of visits and levels of hospitals had persistently effects on all the measures. Our analysis revealed sub-optimal diabetes care in Taiwan and concluded the importance of enhancing care quality from primary settings.
\end{abstract}

(C) 2005 Elsevier Ireland Ltd. All rights reserved.

Keywords: Professional accountability; Diabetes care measures; National Health Insurance claims data; Taiwan

\section{Introduction}

With $4 \%$ prevalence in total population, diabetic population is estimated to be over 1,000,000 in Taiwan

* Corresponding author. Tel.: +886 23516478x28; fax: +886223920456 .

E-mail address: mslai@episerv.cph.ntu.edu.tw (M.-S. Lai).
[1]. It was reported that the majority of patients in Taiwan had unsatisfactory glycemic control and high prevalence of diabetic complications [2]. As the fourth leading cause of death, diabetes caused 44.38 deaths per 100,000 persons and consumed more than 320 million US dollars in the year 2003 [1]. Trying to improve the quality of diabetic care, Taiwan had established the practice guideline for diabetic care, 
implemented accreditation for diabetes mellitus (DM) care institutions and set up the shared care networks in 25 counties [3].

The professional accountability, presented by adequacy of laboratory monitoring for diabetic patients, was widely accepted as an indicator of quality assessment for diabetes care in process domain [4-18]. The accountability for diabetes care in Taiwan was first evaluated in a regional teaching hospital in 1996 [19]. This report and the following studies revealed deficit in diabetes care in Taiwan [19-21]. The National Health Insurance (NHI) program provided nationwide coverage for medical care in Taiwan since 1995. As of April 2003, there were $21,869,478$ individuals enrolled in the NHI with a coverage rate of $96 \%$ [22]. Whether the comprehensive medical insurance in Taiwan had improved the quality of diabetes care or not is an interesting topic. Utilizing the NHI claims data, the present study was designed to evaluate the adherence to diabetes care measures in Taiwan and to elucidate the determining factors of professional accountability for diabetes care.

\section{Materials and methods}

\subsection{Study design and population}

This study was approved by the National Taiwan University Hospital Research Ethics Committee.

The Bureau of NHI included six branches. Among them, the Taipei Branch enrolled about one-third population in Taiwan. The year 2001 NHI Taipei branch claims data, with linkage to National Mortality database, were kindly supplied by the Office of Statistics, Department of Health, Executive Yuan. The identification code for each patient or physician was masked under the confidentiality consideration. The database supplied information such as gender and birth date of the patients, codes of hospitals or clinics, date of hospital visit, codes of diagnosis, medications, examinations and managements, etc. Detail information about the coding systems and further information of the hospital characteristics could be obtained from the websites [23,24]. The claims data with diagnosis of diabetes was recognized when the first three digits revealed "250" in ICD-9-CM coding system. We had reported that number of outpatient visits, number of hospitalizations, age of the patient, and the level of the hospital were significant independent factors associated with diagnosis accuracy [25]. We followed the predicting model established to assure the accuracy of diagnosis for diabetes. Claims data of 2259 diabetic patients were then sampled out randomly. The demographic and clinical characteristics of the patients were identified. Sex, age, hypoglycemic medications (DM drugs), anti-hypertensive medications (BP drugs), lipid lowering medications (lipid drugs), frequencies of visiting emergency service (ES) or being hospitalization (admission), counts of visiting out patient clinics (OPD), ever received hemodialysis, retina laser therapy or amputation within the study year were included as parameters of patient case-mix. The characteristics of hospitals were considered in different domains. They were classified into four levels: academic medical centers (center), metropolitan hospitals (regional), local community hospitals (local) and physician clinics (clinics). The ownerships of the hospitals or clinics were considered as public or private. The locales of the hospitals included the Taipei City (TC), I-Lan County (IL), Keelung City (KL) and Taipei County (TH). The accreditation for the DM care institutions was classified as center (DMC), unit (DMU), team (DMT) or none (DMN).

\subsection{Evaluation of the performance of diabetes care measures}

Frequencies of diabetes care measures were recorded under categories of plasma glucose (glucose), hemoglobin $A_{1 C}\left(A_{1 C}\right)$, renal function test (RFT), liver function test (LFT), plasma lipid profile (lipid), urinalysis (urine), urine microalbumin, and eye ground exam (eye). Blood glucose included fasting and postprandial glucose checkup. RFT included serum creatinine and blood urea nitrogen (BUN). LFT included serum aspartate aminotransferase (AST) and alanine aminotransferase (ALT). Lipid included total cholesterol, triglyceride, HDL cholesterol (HDL-C) and LDL cholesterol (LDL-C). Urinalysis included urine microalbumin and urine routine. When more than one laboratory examinations under the same category were claimed in one OPD or ES visit or during one hospitalization period, the frequency of the examinations of that category was counted as once 
only. Adherence to the measure was considered as positive when the exam was performed at least once within the year.

\subsection{Statistical analysis}

Excel 7.0 for Windows and SAS 10.0 for Windows were used for data management and statistical analysis. We analyzed the influencing factors of diabetes care performance in three different ways. The first part of our analysis was performed from the patient-centered view. Frequencies of laboratory monitor in the year for each patient, no matter in which hospital or clinics, were summed up. The effects of patient characteristics on the performance of laboratory measures were evaluated by Chi-square test. The second part analysis was made from the hospital-centered view. The adherence of laboratory monitor for patients in each hospital or clinics was evaluated with the influencing effects of hospital characteristics analyzed by Chi-square test. To reduce the possible confounding oriented from multiple care unit visits by one patient, we further identified the major care institution with maximal frequency of visits for each patient. Only the laboratory exams in the major care unit for each patient were counted. The mixed effects of patient and hospital characteristics on the accountability were then evaluated by stepwise multiple logistic regression analysis. Patient case-mix and characteristics of the major care unit were independent variables. Adherence to the diabetes care measure was the dependent variable. The magnitude of the association of each independent variable with the outcome variable was calculated using odds ratios (ORs) and 95\% confidence intervals (CIs). Only significant values in the final logistic regression model were presented. We did not analyze the possible effects of physician factors such as age or specialty for it was not recorded in the database. Continuous variables were presented as mean \pm standard deviation. A $p$-value of $<0.05$ was considered as statistically significant.

\section{Results}

The data of 1078 male (47.7\%) and 1181 female $(52.3 \%)$ diabetic patients of mean age $64.1 \pm 13.1$ years (range: 11-98 years) were included in our analysis. The mean annual frequency of OPD visit for each patient was $21.7 \pm 18.1$ (range: $1-176)$. Seventyone patients ( 38 male and 33 female) died within the year. The rate of ever admission to hospitals within the year was $19.9 \%$ (male: $22.7 \%$, female: $17.3 \%$ ). A total of 469 patients $(20.8 \%)$ had ever visited emergency service for their acute medical conditions in that year. Identified by ICD-9 disease coding, a total of 983 patients $(43.5 \%)$ were recorded as having retinopathy, nephropathy or neuropathy. Analyzed by the treatment coding, we identified 36 patients $(1.59 \%)$ under regular hemodialysis, 45 patients $(1.99 \%)$ under retinal laser therapy and 12 patients $(0.53 \%)$ amputated in that year. The diabetic medications were given to 1651 (73.1\%) patients, with oral hypoglycemic agent (OHA) alone in 1323 patients (58.6\%), insulin alone in 82 patients (3.6\%), both OHA and insulin in 246 patients (10.9\%). Antihypertensive agents were given to $26 \%$ of the patients. About $20.4 \%$ of the patients received lipidlowering medications.

The average annual frequencies of exams for each patient were calculated as following: glucose $4.7 \pm 4.8(0-40), \mathrm{A}_{1 \mathrm{C}} 1.0 \pm 1.5(0-11)$, urinalysis $1.0 \pm 2.1 \quad(0-40), \quad$ RFT $1.5 \pm 2.2 \quad(0-21)$, lipid $1.4 \pm 1.7(0-13)$, LFT $1.3 \pm 1.9(0-20)$ and eye ground $0.4 \pm 1.5(0-22)$. The percentages of patients who ever received examinations within the year (at least once) were: glucose $76.3 \%, \mathrm{~A}_{1 \mathrm{C}} 42.7 \%$, urinalysis $40.2 \%$, RFT $59.7 \%$, lipid $59.2 \%$, LFT $53.2 \%$, eye ground $16.8 \%$. There were 433 patients $(19.2 \%)$ who never received any one laboratory monitoring within the year. Urine microalbumin was checked only in eight patients $(0.35 \%)$.

In our series, 128 patients had the ICD-9 coding related to type 1 diabetes (250.x1 or 250.x3). Among them, 93 patients did not receive insulin therapy. If the related ICD-9 coding and insulin therapy were accepted as diagnosis criteria for type 1 diabetes, only $1.5 \%$ (35 out of 2259) of our patients would be type 1 patients. These patients had a mean age of $43.9 \pm 20.9$ years, average annual counts of visits $25.9 \pm 15.2$ (5-60), admission rate $37.1 \%$ and ES visiting rate $34.3 \%$. Comparing to other patients, type 1 patients had higher adherence rates to glucose testing (100\% versus $75.9 \%), \quad \mathrm{HbA}_{1 \mathrm{C}}$ measure $(82.9 \%$ versus $42.0 \%)$, urinalysis (68.6\% versus $39.8 \%)$, RFT ( $85.7 \%$ versus $59.3 \%)$, lipid profile $(82.9 \%$ versus $58.8 \%)$, LFT 
(71.4\% versus $52.9 \%)$ and eye exams $(37.1 \%$ versus $16.5 \%$ ). To minimize potential biases, we excluded the 35 patients and performed following statistical analysis with focus on the remaining 2224 patients.
Diabetic patients with DM drugs, BP drugs, lipid drugs, ES visit, admission, frequent OPD visits had higher adherence for all the diabetes care measures (Table 1). Male patients had higher adherence to the

Table 1

Percentage of patients ever received diabetes care measures, by patient characteristics

\begin{tabular}{|c|c|c|c|c|c|c|c|c|}
\hline & \multirow[t]{2}{*}{ Patient number } & \multicolumn{7}{|c|}{ Percentage of patients whoever received exams } \\
\hline & & Glucose & $\mathrm{A}_{1 \mathrm{C}}$ & Urine & RFT & Lipid & LFT & Eye \\
\hline \multicolumn{9}{|l|}{ Gender } \\
\hline Male & 1061 & $81.8^{\S}$ & $46.1^{\ddagger}$ & $42.9^{\dagger}$ & $63.9^{\S}$ & $61.6^{\dagger}$ & $56.7^{\ddagger}$ & 15.8 \\
\hline Female & 1163 & 70.6 & 38.4 & 36.9 & 55.0 & 56.2 & 49.4 & 17.1 \\
\hline \multicolumn{9}{|l|}{ Age } \\
\hline$<45$ & 160 & $69.4^{\dagger}$ & 45.0 & $35.0^{\ddagger}$ & $51.3^{\S}$ & 51.9 & $48.1^{\dagger}$ & $9.4^{*}$ \\
\hline $45-64$ & 900 & 73.3 & 40.4 & 35.3 & 53.9 & 58.3 & 49.0 & 16.7 \\
\hline$>65$ & 1164 & 78.9 & 42.9 & 43.8 & 64.5 & 60.1 & 56.5 & 17.4 \\
\hline \multicolumn{9}{|l|}{ DM drugs } \\
\hline None & 608 & $31.1^{\S}$ & $5.9^{\S}$ & $20.9^{\S}$ & $28.5^{\S}$ & $25.5^{\S}$ & $27.5^{\S}$ & $9.5^{\S}$ \\
\hline OHA & 1323 & 91.8 & 53.6 & 41.0 & 66.6 & 69.2 & 57.9 & 18.2 \\
\hline Insulin & 66 & 92.4 & 54.6 & 59.1 & 80.3 & 68.2 & 74.2 & 31.8 \\
\hline Combine & 227 & 98.7 & 67.8 & 77.5 & 93.0 & 85.0 & 85.5 & 20.7 \\
\hline \multicolumn{9}{|l|}{ BP drugs } \\
\hline No & 1646 & $70.2^{\S}$ & $37.1^{\S}$ & $33.8^{\S}$ & $52.1^{\S}$ & $52.1^{\S}$ & $46.8^{\S}$ & $15.0^{\ddagger}$ \\
\hline Yes & 578 & 92.4 & 56.2 & 56.8 & 79.8 & 78.0 & 70.2 & 20.9 \\
\hline \multicolumn{9}{|l|}{ Lipid drugs } \\
\hline No & 1769 & $70.6^{\S}$ & $37.3^{\S}$ & $37.3^{\S}$ & $53.8^{\S}$ & $49.2^{\S}$ & $47.2^{\S}$ & 15.8 \\
\hline Yes & 455 & 96.7 & 60.4 & 49.5 & 80.7 & 96.3 & 75.0 & 19.1 \\
\hline \multicolumn{9}{|l|}{ Admission } \\
\hline No & 1788 & $70.4^{\S}$ & $39.8^{\S}$ & $29.4^{\S}$ & $49.8^{\S}$ & $52.7^{\S}$ & $42.5^{\S}$ & $15.0^{\S}$ \\
\hline Yes & 436 & 98.9 & 51.4 & 82.1 & 98.2 & 83.9 & 95.6 & 22.7 \\
\hline \multicolumn{9}{|l|}{ ES visit } \\
\hline No & 1767 & $71.1^{\S}$ & $39.6^{\S}$ & $32.7^{\S}$ & $51.5^{\S}$ & $54.7^{\S}$ & $44.8^{\S}$ & $15.6^{*}$ \\
\hline Yes & 457 & 94.5 & 51.6 & 67.2 & 89.3 & 74.8 & 84.3 & 19.9 \\
\hline \multicolumn{9}{|c|}{ Counts of visit } \\
\hline$<4$ & 292 & $21.2^{\S}$ & $4.1^{\S}$ & $12.7^{\S}$ & $17.1^{\S}$ & $11.6^{\S}$ & $16.8^{\S}$ & $3.1^{\S}$ \\
\hline $4-8$ & 195 & 50.3 & 13.9 & 24.6 & 36.9 & 28.7 & 31.8 & 8.7 \\
\hline$\geq 8$ & 1737 & 88.0 & 51.6 & 46.0 & 68.9 & 70.1 & 61.3 & 19.6 \\
\hline \multicolumn{9}{|c|}{ Hemodialysis } \\
\hline No & 2189 & 75.7 & 42.3 & $39.5^{*}$ & $58.8^{\ddagger}$ & 58.6 & $52.4^{\S}$ & 16.4 \\
\hline Yes & 35 & 88.6 & 28.6 & 57.1 & 88.6 & 74.3 & 85.7 & 22.9 \\
\hline \multicolumn{9}{|l|}{ Laser Tx } \\
\hline No & 2183 & $75.6^{*}$ & $41.6^{\dagger}$ & $39.3^{\dagger}$ & 59.0 & 58.5 & 52.7 & $15.0^{\S}$ \\
\hline Yes & 41 & 92.7 & 63.4 & 63.4 & 73.2 & 73.2 & 63.4 & 97.6 \\
\hline \multicolumn{9}{|l|}{ Amputation } \\
\hline No & 2212 & 75.9 & 41.9 & $39.5^{\dagger}$ & $59.1^{*}$ & $58.6^{*}$ & $52.7^{\dagger}$ & $16.4^{*}$ \\
\hline Yes & 12 & 83.3 & 66.7 & 83.3 & 91.7 & 91.7 & 91.7 & 41.7 \\
\hline
\end{tabular}


diabetes care measures, except the eye exam, than female patients. Higher percentage of aged patients had received glucose, urine, RFT and LFT than younger patients. Patients under regular hemodialysis, ever received retina laser therapy or amputation within the year had higher adherence to some, but not all, of the measures.

The 2224 patients visited 1323 hospitals or clinics. In this series, 1644 patients ( $73.9 \%$ ) visited more than one care unit within the year. The average number of hospital or clinics visited by each patient was $3.1 \pm 2.1$ (maximum 14). For each patient, the frequency of OPD visit in one particular institution varied from 1 to 143 (mean 7.0 \pm 9.2). The associations of the percentage of patients ever received diabetes care measures with the hospital characteristics were summarized as Table 2. Medical centers had highest adherence for diabetes care measures, followed by regional hospitals, local community hospitals and physician clinics. The public hospitals had better performance in laboratory monitoring for their diabetic patients than private hospitals or clinics. Medical institutions located in Taipei City had highest performance in diabetes care measures, while those located in Taipei County had lowest adherence of laboratory monitoring for their diabetic patients. Significant difference of diabetes care measures existed between qualified DM care institutions and non-qualified hospitals or clinics. Among qualified DM care institutions, hospitals classified as centers, units or teams did not show significant difference in hospital accountability in diabetes care.

A total of 1493 patients $(67.1 \%)$ visited medical centers, regional hospitals or local hospitals as their major care units, while 731 patients (32.9\%) received most of their medical care just from primary physician clinics. The mixed effects of patient or hospital characteristics on the professional accountability in each patient's major care unit were summarized as Table 3. The effects of sex and regular hemodialysis on professional accountability were not significant. Increasing age slightly decreased performance for $\mathrm{A}_{1 \mathrm{C}}$ and lipid measures. Patients with DM drugs, BP drugs,

Table 2

Percentage of patients ever received diabetes care measures, by hospital characteristics

\begin{tabular}{|c|c|c|c|c|c|c|c|c|c|}
\hline & \multirow[t]{2}{*}{ Care unit number } & \multirow[t]{2}{*}{ Patient number } & \multicolumn{7}{|c|}{ Percentage of patients whoever received exams } \\
\hline & & & Glucose & $\mathrm{A}_{1 \mathrm{C}}$ & Urine & RFT & Lipid & LFT & Eye \\
\hline \multicolumn{10}{|l|}{ Levels } \\
\hline Centers & 5 & 1044 & $65.4^{\S}$ & $39.2^{\S}$ & $36.7^{\S}$ & $53.5^{\S}$ & $46.6^{\S}$ & $46.3^{\S}$ & $13.2^{\S}$ \\
\hline Regional & 22 & 1238 & 57.4 & 30.3 & 28.5 & 49.1 & 43.6 & 43.3 & 9.2 \\
\hline Local & 60 & 850 & 40.2 & 14.1 & 18.7 & 26.8 & 24.9 & 23.5 & 3.3 \\
\hline Clinics & 1236 & 3721 & 12.1 & 3.3 & 4.3 & 6.3 & 7.6 & 5.7 & 3.5 \\
\hline \multicolumn{10}{|l|}{ Ownerships } \\
\hline Public & 76 & 1851 & $54.5^{\S}$ & $28.7^{\S}$ & $26.6^{\S}$ & $42.7^{\S}$ & $39.7^{\S}$ & $37.0^{\S}$ & $8.4^{\S}$ \\
\hline Private & 1247 & 5002 & 23.5 & 9.9 & 11.2 & 16.8 & 15.7 & 14.9 & 5.1 \\
\hline \multicolumn{10}{|l|}{ Locales $^{\mathrm{a}}$} \\
\hline TC & 505 & 4088 & $38.5^{\S}$ & $20.3^{\S}$ & $20.3^{\S}$ & $30.7^{\S}$ & $28.4^{\S}$ & $27.2^{\S}$ & $7.2^{\S}$ \\
\hline TH & 666 & 2180 & 19.5 & 5.2 & 6.9 & 11.2 & 11.0 & 10.2 & 3.6 \\
\hline IL & 75 & 322 & 34.8 & 12.7 & 13.4 & 22.7 & 19.6 & 18.0 & 5.6 \\
\hline KL & 77 & 263 & 27.4 & 16.4 & 11.4 & 22.4 & 20.9 & 15.2 & 6.1 \\
\hline \multicolumn{10}{|c|}{ DM care institutions ${ }^{\mathrm{b}}$} \\
\hline DMC & 7 & 1008 & $65.5^{\S}$ & $40.3^{\S}$ & $35.4^{\S}$ & $52.7^{\S}$ & $46.5^{\S}$ & $45.6^{\S}$ & $13.1^{\S}$ \\
\hline DMU & 9 & 516 & 55.0 & 28.9 & 29.3 & 48.1 & 39.0 & 40.3 & 11.6 \\
\hline DMT & 6 & 253 & 62.1 & 33.2 & 30.8 & 51.0 & 51.4 & 49.0 & 6.7 \\
\hline DMN & 1301 & 5076 & 21.3 & 7.7 & 9.2 & 14.2 & 14.2 & 12.6 & 3.9 \\
\hline
\end{tabular}

The total patient number was counted to be 6853 for one patient could visit more than one hospital or clinic. ${ }^{*} p<0.05,{ }^{\dagger} p<0.01,{ }^{\ddagger} p<0.001$, ${ }^{\S} p<0.0001$, by Chi-square test.

${ }^{\text {a }}$ Locales: TC: Taipei City, IL: I-Lan County, KL: Keelung City, TH: Taipei County.

${ }^{b}$ DM care institutions accreditation: centers (DMC), units (DMU), teams (DMT), none (DMN). 
Table 3

Odds ratios (with 95\% confidence interval) of significant patient and hospital characteristics for adherence to diabetes care measures in the major care institution by stepwise multiple logistic regression model

\begin{tabular}{|c|c|c|c|c|c|c|c|}
\hline & Glucose & $A_{1 C}$ & Urine & RFT & Lipid & LFT & Eye \\
\hline Age (per year) & & $\begin{array}{l}0.984^{\ddagger} \\
(0.976-0.993)\end{array}$ & & & $\begin{array}{l}0.985^{\dagger} \\
(0.977-0.994)\end{array}$ & & \\
\hline $\begin{array}{l}\text { DM drugs } \\
\quad \text { (yes vs. no) }\end{array}$ & $\begin{array}{l}23.874^{\S} \\
(17.787-32.044)\end{array}$ & $\begin{array}{l}16.582^{\S} \\
(11.550-23.806)\end{array}$ & $\begin{array}{l}2.537^{\S} \\
(1.935-3.327)\end{array}$ & $\begin{array}{l}4.398^{\S} \\
(3.407-5.677)\end{array}$ & $\begin{array}{l}5.867^{\S} \\
(4.532-7.596)\end{array}$ & $\begin{array}{l}3.040^{\S} \\
(2.371-3.898)\end{array}$ & \\
\hline $\begin{array}{l}\text { BP drugs } \\
\quad \text { (yes vs. no) }\end{array}$ & $\begin{array}{l}1.550^{*} \\
(1.027-2.338)\end{array}$ & & $\begin{array}{l}1.374^{*} \\
(1.066-1.772)\end{array}$ & $\begin{array}{l}1.774^{\S} \\
(1.341-2.346)\end{array}$ & $\begin{array}{l}1.904^{\S} \\
(1.429-2.538)\end{array}$ & & \\
\hline $\begin{array}{l}\text { Lipid drugs } \\
\quad \text { (yes vs. no) }\end{array}$ & $\begin{array}{l}7.128^{\S} \\
(3.952-12.856)\end{array}$ & $\begin{array}{l}1.611^{\ddagger} \\
(1.236-2.100)\end{array}$ & & $\begin{array}{l}2.759^{\S} \\
(2.046-3.721)\end{array}$ & $\begin{array}{l}29.495^{\S} \\
(16.619-52.345)\end{array}$ & $\begin{array}{l}2.660^{\S} \\
(2.032-3.483)\end{array}$ & \\
\hline $\begin{array}{l}\text { ES visit } \\
\quad \text { (yes vs. no) }\end{array}$ & $\begin{array}{l}5.541^{\S} \\
(2.657-11.555)\end{array}$ & & $\begin{array}{l}2.421^{\S} \\
(1.706-3.437)\end{array}$ & $\begin{array}{l}5.363^{\S} \\
(3.098-9.283)\end{array}$ & & $\begin{array}{l}3.556^{\S} \\
(2.302-5.495)\end{array}$ & \\
\hline $\begin{array}{l}\text { Counts of visit } \\
\text { (per one visit) }\end{array}$ & $\begin{array}{l}1.027^{\ddagger} \\
(1.013-1.042)\end{array}$ & $\begin{array}{l}1.028^{\S} \\
(1.018-1.039)\end{array}$ & $\begin{array}{l}1.031^{\S} \\
(1.021-1.041)\end{array}$ & $\begin{array}{l}1.024^{\S} \\
(1.013-1.035)\end{array}$ & $\begin{array}{l}1.030^{\S} \\
(1.019-1.041)\end{array}$ & $\begin{array}{l}1.020^{\S} \\
(1.010-1.029)\end{array}$ & $\begin{array}{l}1.034^{\S} \\
(1.024 \sim 1.044)\end{array}$ \\
\hline $\begin{array}{l}\text { Levels (hospitals } \\
\text { vs. clinics) }\end{array}$ & $\begin{array}{l}3.331^{\S} \\
(2.446-4.536)\end{array}$ & $\begin{array}{l}3.067^{\S} \\
(2.290-4.107)\end{array}$ & $\begin{array}{l}1.884^{\S} \\
(1.396-2.543)\end{array}$ & $\begin{array}{l}2.694^{\S} \\
(2.100-3.457)\end{array}$ & $\begin{array}{l}2.504^{\S} \\
(1.918-3.268)\end{array}$ & $\begin{array}{l}2.076^{\S} \\
(1.626-2.650)\end{array}$ & $\begin{array}{l}1.785^{\dagger} \\
(1.188 \sim 2.680)\end{array}$ \\
\hline $\begin{array}{l}\text { Ownerships } \\
\quad \text { (public vs. private) }\end{array}$ & $\begin{array}{l}1.787^{\ddagger} \\
(1.319-2.419)\end{array}$ & $\begin{array}{l}1.350^{*} \\
(1.074-1.696)\end{array}$ & & $\begin{array}{l}1.441^{\dagger} \\
(1.149-1.806)\end{array}$ & $\begin{array}{l}1.436^{\dagger} \\
(1.136-1.815)\end{array}$ & $\begin{array}{l}1.320^{*} \\
(1.063-1.639)\end{array}$ & \\
\hline $\begin{array}{l}\text { DM care institutions } \\
\text { (yes vs. no) }^{\mathrm{b}}\end{array}$ & & $\begin{array}{l}1.845^{\S} \\
(1.460-2.330)\end{array}$ & $\begin{array}{l}1.278^{*} \\
(1.011-1.615)\end{array}$ & & & & $\begin{array}{l}2.029^{\S} \\
(1.468 \sim 2.804)\end{array}$ \\
\hline
\end{tabular}

Patient case-mix and characteristics of the major care unit for individual patient were independent variables. Adherence to the diabetes care measure was the dependent variable. Statistical significance was evaluated by stepwise multivariate logistic regression. The adjusted ORs (95\% CI) of significant factors (patient case-mix or hospital characteristics) on each outcome variable (adherence to measures) in the final model were shown with ${ }^{*} p<0.05,{ }^{\dagger} p<0.01,{ }^{\ddagger} p<0.001,{ }^{\S} p<0.0001$. Odds ratios without statistical significance were not shown in the table.

${ }^{\text {a }}$ Hospital locales. TH means Taipei County.

b DM care institutions included DM centers, units and teams. 
lipid drugs, admission and ES visit had higher adherence for most of the laboratory measures. Public care units had higher performance in most of the laboratory measures than private care units. Taipei County generally had lower adherence for laboratory monitor than other areas. Care institutions passed accreditation for DM care had higher performance in $\mathrm{A}_{1 \mathrm{C}}$, urine and eye ground checkup than those not qualified. Over all, the frequency of visits and the hospital levels remained persistently as significant indicators for receiving all the laboratory measures.

\section{Discussion}

The present study used NHI claims data to analyze hospital accountability for diabetes care. Limits on presenting clinical details by the ICD-9 coding system and problems related to financial incentives may lead to bias in coding and thus result in misclassification of patients. To minimize possible inaccuracy in sampling out data, the present study used a predicting model to assure the accuracy for the DM diagnosis [25]. The representative and the generalizability of our data were acceptable for the age distribution, the sex ratio, the admission rate, the ES visiting rate and the mortality rate of our 2259 sample patients were similar to previous reports $[2,21,26,27]$.

Majority of diabets patients in Taiwan are type 2 diabetes [26]. The estimated ratio of type 1 patients recruited in this series $(1.5 \%)$ was similar to what reported previously $[2,21]$. Type 1 diabetes patients had more frequent visits and more frequent clinical tests than type 2 patients. This fact highlights the importance of considering patient case-mix in evaluating quality of diabetes care.

Previous literatures did not include adherence to LFT as an indicator [4-18]. We had demonstrated a high prevalence of abnormal liver function in diabetes patients and suggested adding LFT to the practice guideline for safety medication consideration [19]. LFT is now recommended as one necessary diabetes care measure in NHI quality-based payment program [22]. We therefore included adherence to LFT as one indicator in our analysis.

The Bureau of NHI contracted 17,022 medical institutions, which was $93.82 \%$ of medical institutions nationwide [22]. With convenient transportation and no strict regulation in the referral process, people in Taiwan have free access to medical care. With minimal co-payment and fee-for-service payment method, NHI program indirectly provides incentives for unnecessary healthcare services $[28,29]$. The observations of multiple care unit visits $(3.1 \pm 2.1$, maximum 14) and frequent OPD visits (mean $21.7 \pm 18.1$, maximum 176) of our diabetic patients revealed the convenience of seeking medical care in Taiwan. The high maximal counts of the exams in the year, such as 11 for $A_{1 C}$ measures, also revealed frequent laboratory measures in some patients. However, the adherence to necessary diabetes care measures was rather inadequate in majority of our patients. The percentage of patients ever received $\mathrm{A}_{1 \mathrm{C}}$ or eye exam in Taiwan was 42.7 and $16.8 \%$, respectively, which was significantly lower than what reported in USA [4-18]. In our series, only eight patients in one hospital had ever received urine microalbumin exam. The extremely low adherence to urine microalbumin check-up and the finding that about $19.2 \%$ of our diabetic patients never received any one of the laboratory measures within the year further suggested the importance of improving professional accountability in Taiwan.

Patient characteristics such as old age, male in gender, with DM drugs, with BP or lipid drugs, ever admitted, ever visited ES, and frequent OPD visits had significant associations with the performance in most, or all, of the diabetes care measures while evaluated from the patient-centered analysis. Those findings supported our hypothesis that not only demographic characteristics but also the clinical conditions and comorbidities would influence the hospital accountability on diabetes care measures. Previous studies had reported the strong association of insulin use with $\mathrm{HbA}_{1 \mathrm{C}}$ testing, various effects of different age groups on the $\mathrm{HbA}_{1 \mathrm{C}}$ and lipid profile measurement, and higher likelihood of more frequent visits on standard diabetes care measures $[9,10,13]$. In our study, the significance of those influencing effects varied after adjustment for both the patient and hospital characteristics. Male patients had higher rate of hospitalization and higher rate of receiving hypoglycemic medications. The predominance of male in receiving laboratory measures disappeared after adjustment for other clinical and hospital factors. Patients of old age were initially shown as more likely to receive 
measures for glucose, urine, RFT and LFT than younger patients. However, the influencing effects of age on those measures disappeared after adjustment for clinical and hospital characteristics. Furthermore, increasing in age inversely decreased the performance of $\mathrm{A}_{1 \mathrm{C}}$ and lipid measures. After adjustment, the influencing effects of DM drugs, BP drugs, lipid drugs, admission and ES visit persisted for most, though not all, of the diabetes care measures. In terms of adherence to diabetes care measures, clinical conditions appeared to be more significant determining factors than demographic factors. Adjusting for other patient characteristics and hospital factors, frequency of visits persistently remained as significant determining factors for adherence to all the diabetes measures. In research concerning the process of diabetes care, the importance of adjustment for the frequency of visits should never be neglected.

Our data clearly revealed the influence of hospital characteristics on the performance of professional accountability. With sufficient manpower and resources, hospitals higher in levels not surprisingly showed better performance in diabetes care measures. Comparing to public sectors, the private care units had lower performance in diabetes care measures. This discrepancy could partly be explained by variations of budget control in institutions with different ownerships. In our series, private sectors included more physician clinics and fewer hospitals than public sectors. This fact could also cause the observed discrepancy in accountability for diabetes care. The present study also elucidated different accountability for diabetes care measures in different locales. The lowest performance in accountability of Taipei County could be explained by its delay in establishing diabetes shared care network and relative poor medical resources in its wide suburban area. The qualified DM care institutions were expected to have better accountability for having well-educated manpower and with adherence to diabetes care practice guideline were included as minimal requirement for accreditation. Variations in diabetes management in different primary care settings of the same hospital or in different types of care units had been reported [1518]. Patients with specific characteristics may choose and remain with some specific physicians or care units as their major care providers. Greenfield et al. concluded that inclusion of patient case-mix variables reduced the statistical significance of specialty differences for some quality measures [14]. Our data revealed significant influencing effects of hospital characteristics on the diabetes care even after adjustment for the patient characteristics. In the past, governmental policy in Taiwan for enhancing quality of diabetes care usually focused on hospitals higher in levels, or institutions passed DM care accreditation. Since physician clinics or non-qualified DM care units were the major care units for lots of our diabetic patients, we would like to emphasize the importance of enhancing quality of diabetes care from the primary settings.

This study had several limitations. First, even with diagnosis accuracy predicting model, misclassification of patients still might exist. Second, this study was limited in evaluating quality of diabetes care in outcome domain. Third, effects of physician factors on the professional accountability were not accessed. Fourth, people in Taiwan had some misconceptions about the illness of diabetes [30]. Influences of sociocultural factors on the non-adherence to diabetes care measures were not analyzed. Fifth, hospital or doctor shopping is common in some patients. Information concerning the continuity of diabetes care was not attainable in detail. We did not include the factors of continuity of care in our analysis. Sixth, healthcare resources varied in different geographical areas [31]. Effects of medical resources distribution on diabetes care were not assessed. Seventh, NHI policy would influence physician performance and patterns of healthcare utilization $[28,29,32]$. The effects of health system-related factors on diabetes care were not explored in this study.

The costs of diabetic patients increase rapidly under NHI program $[33,34]$. How to improve the quality of diabetes care cost-effectively is an important issue. This study evaluated the quality of diabetes care in Taiwan and demonstrated the effects of various patient and hospital characteristics on the accountability for diabetes care. We highlighted the importance of considering the level of the major care unit and the frequency of visits for each patient in the research of accountability for diabetes care. With nationwide medical insurance, the performance of diabetes care in Taiwan still is sub-optimal. The accountability for diabetes care should be further enhanced, especially from the primary settings. 


\section{Acknowledgement}

This study was supported by a grant from Bureau of Health Promotion, Department of Health, Taiwan (DOH 92-HP-1108).

\section{References}

[1] Health and vitae statistics, year 2003, available from: Health and National Health Insurance Annual Statistics Information Service, http://www.doh.gov.tw/EN/Webpage, accessed on: 19 April 2005.

[2] L.M. Chuang, S.T. Tsai, B.Y. Huang, T.Y. Tai, Diabcare (Taiwan) Study Group, The current state of diabetes management in Taiwan, Diab. Res. Clin. Pract. 54 (Suppl. 1) (2001) S55-S65.

[3] R.H. Weng, R.S. Shiu, Y.C. Hsieh, Current status of diabetes shared care in Taiwan, Formos. J. Med. 6 (2002) 569-573.

[4] M.H. Chin, S.B. Auerbach, S. Cook, J.F. Harrison, J. Koppert, L. Jin, et al. Quality of diabetes care in community health centers, Am. J. Public Health 90 (2000) 431-434.

[5] B.B. Fleming, S. Greenfield, M.M. Engelgau, L.M. Pogach, S.B. Clauser, M.A. Parrott, the DQIP Group, The Diabetes Quality Improvement Project: moving science into health policy to gain an edge on the diabetes epidemic, Diab. Care 24 (2001) 1815-1820.

[6] K.J. Acton, R. Shields, S. Rith-Najarian, B. Tolbert, J. Kelly, K. Moore, et al. Applying the Diabetes Quality Improvement Project indicators in the Indian Health Service primary care setting, Diab. Care 24 (2001) 22-26.

[7] M.R. McClain, D.E. Wennberg, R.W. Sherwin, W.C. Steinmann, J.C. Rice, Trends in the Diabetes Quality Improvement Project measures in Maine from 1994 to 1999, Diab. Care 26 (2003) 597-601.

[8] G.L.A. Beckles, W.H. Herman, M.M. Engelgau, R.E. Aubert, K.M. Venkat Narayan, D.F. Williamson, Population-based assessment of the level of care among adults with diabetes in the U.S., Diab. Care 21 (1998) 1432-1438.

[9] R.A. Bell, F. Camacho, K. Goonan, V. Duren-Winfield, R.T. Anderson, J.C. Konen, et al. Quality of diabetes care among low-income patients in North Carolina, Am. J. Prev. Med. 21 (2001) 124-131.

[10] M. Srinivasan, M. Przybylski, N. Swigonski, The Oregon Health Plan: predictors of office-based diabetic quality of care, Diab. Care 24 (2001) 262-267.

[11] D.R. Arady, B.B. Fleming, D.K. Keller, P.W. Pendergrass, R.J. Vaughn, J.M. Tuppin, et al. Variation in diabetes care among states. Do patient characteristics matter? Diab. Care 25 (2002) 2230-2237.

[12] M. Heisler, D.M. Smith, R.A. Hayward, S.L. Krein, E.A. Kerr, Racial disparities in diabetes care processes, outcomes, and treatment intensity, Med. Care 41 (2003) 1221-1232.

[13] Y. Roubideaux, D. Buchwald, J. Beals, D. Middlebrook, S. Manson, B. Muneta, et al. Measuring the quality of diabetes care for older American Indians and Alaska natives, Am. J. Public Health 94 (2004) 60-65.

[14] S. Greenfield, S.H. Kaplan, R. Kahn, J. Ninomiya, J.L. Griffith, Profiling care provided by different groups of physicians: effects of patient case-mix (bias) and physician-level clustering on quality assessment results, Ann. Intern. Med. 136 (2002) 111-121.

[15] D.S. Porterfield, L. Kinsinger, Quality of care for uninsured patients with diabetes in a rural area, Diab. Care 25 (2002) 319-323.

[16] P. Suwattee, J.C. Lynch, M.L. Pendergrass, Quality of care for diabetic patients in a large urban public hospital, Diab. Care 26 (2003) 563-568.

[17] G. Berardis, F. Pellegrini, M. Fransciosi, M. Belfiglio, B.D. Nardo, S. Greenfield, et al. QuED Study Group, Quality of care and outcomes in type 2 diabetic patients: a comparison between general practice and diabetic clinics, Diab. Care 27 (2004) 398-406.

[18] C. Kim, D.F. Williamson, C.M. Mangione, M.M. Safford, J.V. Selby, D.G. Marrero, et al. the TRAID Study Group, Managed care organization and the quality of diabetes care. The Translating Research into Action for Diabetes (TRIAD) Study, Diab. Care 27 (2004) 1529-1534.

[19] F.Y. Tseng, Quality of medical care for noninsulin-dependent diabetic patients in a community teaching hospital in Taiwan, J. Formos. Med. Assoc. 95 (1996) 414-416.

[20] T.L. Chen, C.H. Lu, T.B. Huang, G.Y. Lin, Out-patient care of persons with diabetes before participation in the shared care program in Chia-Yi area, Public Health Q. 26 (2000) 319-330.

[21] L.M. Chung, S.T. Tsai, B.Y. Huang, T.Y. Tai, The DiabcareAsia 1998 Study Group, The status of diabetes control in Asia-a cross-sectional survey of 24317 patients with diabetes mellitus in 1998, Diab. Med. 19 (2002) 978-985.

[22] Bureau of National Health Insurance, available from http:// www.nhi.gov.tw/00english/e_index.htm, assessed on: 19 April 2005.

[23] Code Books for National Health Insurance Database, available from http://www.nhri.org.tw/nhird/date_02.htm, assessed on: 19 April 2005.

[24] Qualified diabetes care institutions, available from Taiwanese Association of Diabetes Educators: http://www.tade. org.tw/member/tw_map.htm\#top, assessed on: 19 April 2005.

[25] C.C. Lin, M.S. Lai, C.Y. Syu, S.C. Chang, F.Y. Tseng, The accuracy of diabetes diagnosis in health insurance claims data in Taiwan, J. Formos. Med. Assoc. 104 (2005) 157-163.

[26] C.J. Chang, F.W. Lu, Y.C. Yang, J.S. Wu, T.J. Wu, M.S. Chen, et al. Epidemiologic study of type 2 diabetes in Taiwan, Diab. Res. Clin. Pract. 50 (Suppl. 2) (2000) S49-S59.

[27] J.N. Wei, L.M. Chung, R.S. Lin, C.L. Chao, F.C. Sung, Prevalence and hospitalization rates of diabetes mellitus in Taiwan, 1996-2000. Taiwan J. Public Health 21 (2002) 173180.

[28] S.H. Cheng, T.L. Chiang, The effect of universal health insurance on health care utilization in Taiwan: results from a natural experiment, JAMA 278 (1997) 89-93. 
[29] R.E. Chang, W. Lin, C.J. Hsieh, T.L. Chiang, Healthcare utilization patterns and risk adjustment under Taiwan's National Health Insurance System, J. Formos. Med. Assoc. 101 (2002) 52-59.

[30] W.A. Lai, C.Y. Lew-Ting, W.C. Chie, How diabetic patients think about and manage their illness in Taiwan, Diab. Med. 22 (2005) 286-292.

[31] W.C. Lin, H.J. Chang, P.J. Wang, Y.J. Chou, C.H. Lee, Crossregion hospitalization behavior and its related factors in Taiwan, Taiwan J. Public Health 23 (2004) 453-461.
[32] Y.C. Chang, H.E. Liao, The effect of the global budget on the western medicine clinics price and utilization-case of western medicine clinics in the northern Taiwan, Taiwan J. Public Health 21 (2002) 363-372.

[33] T. Lin, P. Chou, M.S. Lai, S.T. Tsai, T.Y. Tai, Direct costs-ofillness of patients with diabetes mellitus in Taiwan, Diab. Res. Clin. Pract. 54 (Suppl. 1) (2001) S43-S46.

[34] T. Lin, P. Chou, S.T. Tsai, Y.C. Lee, T.Y. Tai, Predicting factors associated with costs of diabetic patients in Taiwan, Diab. Res. Clin. Pract. 63 (2004) 119-125. 